\title{
A survey strategy for human respiratory syncytial virus detection among haematopoietic stem cell transplant patients: epidemiological and methodological analysis
}

\author{
Luciana Peniche Moreira', Aripuanã Sakurada Aranha Watanabe', Emerson Carraro ${ }^{2}$, \\ Ellen Ricci Monteiro da Silva', Sandra Baltazar Guatura', Celso Granato', Nancy Junqueira Bellei+ \\ 1Disciplina de Infectologia, Laboratório de Virologia Clínica, Departamento de Medicina, \\ Universidade Federal de São Paulo, São Paulo, SP, Brasil ${ }^{2}$ Universidade Estadual do Centro Oeste, Guarapuava, PR, Brasil
}

\begin{abstract}
Human respiratory syncytial virus (HRSV) causes severe infections among children and immunocompromised patients. We compared HRSV infections among Haematopoietic Stem Cell Transplant program (HSCT) patients and children using direct immunofluorescence (DFA), point-of-care RSV Bio Easy ${ }^{\circledR}$ and a polymerase chain reaction $(P C R)$ assay. Overall, 102 samples from HSCT patients and 128 from children obtained positivity rate of $18.6 \%$ and $14.1 \%$ respectively. PCR sensitivity was highest mainly on samples collected after five days of symptoms onset. A combination of both DFA and reverse transcriptase-PCR methods for HSCT high-risk patients is the best diagnostic flow for HRSV diagnosis among these patients.
\end{abstract}

Key words: respiratory syncytial virus - comparison methods - human stem cell transplant patients

The human respiratory syncytial virus (HRSV) is considered the major cause of lower respiratory tract infections in children (Gardner et al. 1967, Kesson 2007) and an important agent of acute respiratory infection in the elderly and immunocompromised patients accounting for more than $50 \%$ of the mortality rate in human stem cell transplant patients (HSCT) (Ebbert \& Limper 2005).

Several laboratory techniques have been used in the diagnosis of HRSV, differing in sensitivity, cost and time to obtain results (Landry \& Ferguson 2000). The aim of this study was to evaluate the better diagnostic flow for HRSV detection among patients in the HSCT using the following techniques: direct immunofluorescence assay (DFA), immunochromatographic point-of-care RSV Bio $\operatorname{Easy}^{\circledR}(\mathrm{PC})$ assay and polymerase chain reaction (PCR). For evaluation of the possible relation between RSV circulation in community and HSCT patients infection these techniques were applied in conjunction with a community survey among children presenting acute respiratory symptoms suspected of viral infection.

A total of 230 samples were collected from two patient groups presenting with the symptoms of acute respiratory infection from March-December 2008.

In the first group, 102 nasal wash samples were collected from 67 haematological unit patients at the São Paulo Hospital: 36 were stem cell transplant patients, 30 were non-transplant patients and one did not have the record number on this questionnaire, so we could not

Financial support: $\mathrm{CNPq}$

+Corresponding author: nbellei@uol.com.br

Received 30 March 2012

Accepted 19 July 2012 retrieve information about transplant data. Twenty-two patients had more than one sample collected.

The second group included 128 nasopharyngeal aspirates from 119 children from the primary care centre. A questionnaire with epidemiological and clinical aspects for the study was applied. This study was approved by the Ethical Committee of São Paulo Federal University (CEP 0257/2007). Written consent was obtained from all patients or their parents or guardians.

The samples were processed using previously published procedures (Bellei et al. 2007).

The DFA was performed using the Simulfluor Respiratory Screen and Panel kit (Chemicon Int, EUA). A pool of monoclonal antibodies to detect seven respiratory viruses: influenza A (flu), flu B, parainfluenza (PIV) 1, 2 and 3 , adenovirus (Adv) and HRSV.

Nucleic acids were extracted from $200 \mu \mathrm{L}$ aliquots that had been stored at $-80^{\circ} \mathrm{C}$ using the QIAmp DNA Blood kit (Qiagen, Germany), according to the manufacturer's recommendations.

The primers and methodology used for the detection of HRSV on the extracted material have been previously described (Erdman et al. 2003). These primers target the conserved region of the $\mathrm{F}$ gene, which encodes the viral fusion protein and generates a fragment of 380 nucleotide base pairs.

Electrophoresis in a 1.5\% agarose gel (Invitrogen, USA) was performed on each of the amplified products.

Viral isolation was performed using Hep-2 cells cultured using minimum essential medium with $10 \%$ foetal bovine serum and incubated in a $\mathrm{CO}_{2}$ incubator at $37^{\circ} \mathrm{C}$. A tissue culture infectious dose $50\left(\mathrm{TCID}_{50}\right)$ titration of a sample previously isolated in cell culture was performed using the method of Reed and Muench (1938).

The 1:10 dilution made for the $\mathrm{TCID}_{50}$ was used for the reverse transcriptase (RT)-PCR sensitivity test. A viral titre of $1.2 \times 10^{6} \mathrm{TCID}_{50} / \mathrm{mL}$ was found in the con- 
trol sample, and the threshold of detection using RT-PCR was determined to be $0.12 \mathrm{TCID}_{50} / \mathrm{mL}$.

We used the commercial RSV Test Bioeasy kit (Bioeasy, Brazil), a qualitative immunochromatographic assay that detects antigens of HRSV. A hundred tests were provided by the company and they were used to test the samples from the stem cell transplantation program group of patients.

Statistical analyses were performed using a two-bytwo table in Microsoft Office Excel version 2007, fixing the diagnostic RT-PCR as the gold standard. A Fisher exact test was conducted to assess the associations between the categorical variables, with a two-tailed significance level of $p<0.05$. The Kappa test was performed using the $\mathrm{R}$ program version 2.11.1,

Overall, 16.1\% (37/230) of the samples were positive for HRSV. The positivity in the children's group was $14.1 \%(18 / 128)$, while in the HSCT patient group it was $18.6 \%(19 / 102)$.

In the paediatric population, 128 samples were collected from 119 children. Additional samples were only collected from the same child if it occurred 15 days after the end of a previous infection episode, which characterized a new episode. The mean age was 3.2 years (range:

\section{TABLE I}

Number of patients, total number of samples and human respiratory syncytial virus positive samples per haematologic malignancy diagnosis

\begin{tabular}{lccc}
\hline $\begin{array}{l}\text { Underling } \\
\text { disease }\end{array}$ & $\begin{array}{c}\text { Patients } \\
\mathrm{n}(\%)\end{array}$ & $\begin{array}{c}\text { Samples } \\
\mathrm{n}(\%)\end{array}$ & $\begin{array}{c}\text { Positive } \\
\text { samples } \\
\mathrm{n}(\%)\end{array}$ \\
\hline $\begin{array}{lccc}\text { Leukemia } \\
\text { Lymphoma }\end{array}$ & $\begin{array}{l}19(28.8) \\
\text { Other }\end{array}$ & $27(26.7)$ & $4(22.2)$ \\
Total & $66(37.9)$ & $37(36.6)$ & $7(38.9)$ \\
$7(36.9)$ & $101(100)$ & $18(100)$ \\
\hline
\end{tabular}

the median age of these patients was 48 years (range: 5-78 years). The time delay between symptom onset and collection date had a median of three days (range: 1-27 days).
1 month to 11 years). The time from the onset of symptoms until the sample collection date had a mean and median of three days (range: 1 to 12 days).

In the same period, 102 samples from 67 patients with different types of haematologic malignancies were collected (Table I). Among them, 44.8\% (30/66) were non-transplant and $53.7 \%(36 / 66)$ were transplant patients. The patient who had no available information about transplant was excluded from this analysis. Of the remaining 36 transplant patients, 70.6\% (24/34) had allogeneic transplantation and $29.4 \%(10 / 34)$ had autologous transplantation. One of the 67 patients had two distinct episodes of RSV in 2008.

HRSV occurrence was observed between the months of March and September, with a clear peak among children observed in the viral distribution in April. In the HSCT patient group, the distribution was homogeneous between the months of March and June. The frequency of cases in the two groups was similar in the first month of the study.

The percentage of patients positive for HRSV according to each test for the two patients groups are shown in Table II.

In the pediatric group, 11 samples were positive using DFA and RT-PCR, showing a concordance of $94.5 \%$ between these techniques. Three samples were positive via RT-PCR exclusively.

The Fig. 1 shows the distribution of the positive samples among the paediatric and the HSCT patient group according to assay. When the 91 samples were evaluated in parallel, an overall concordance of $84.6 \%$ was observed. When the PC data were excluded and the resulting 102 samples were analyzed with RT-PCR and DFA, seven samples were positive, 83 were negative and 12 were discordant, showing a concordance of $88.4 \%$.

When the RT-PCR assay was used as the gold standard for the paediatric group, the sensitivity, specificity, predictive positive value (PPV), negative predictive value (NPV) and kappa coefficient for DFA were $83.3 \%$, $100 \%, 100 \%, 97.3 \%$ and $0.89 \%$, respectively. For the HSCT group, the sensitivity, specificity, PPV, NPV and kappa coefficient were $50 \%, 94.3 \%, 58.3 \%, 92.2 \%$ and $0.48 \%$ for DFA, respectively, and $33.3 \%, 100 \%, 100 \%$, $90.8 \%$ and $0.46 \%$ for PC, respectively.

The positive cases from the samples of the paediatric group collected more than five days following symptom

TABLE II

Percentage of human respiratory syncytial virus positive patients according to each test for the two groups

\begin{tabular}{|c|c|c|c|c|c|c|}
\hline & \multicolumn{2}{|c|}{$\mathrm{PC}$} & \multicolumn{2}{|c|}{ DFA } & \multicolumn{2}{|c|}{ RT-PCR } \\
\hline & $\begin{array}{c}\text { Tested } \\
\text { samples }\end{array}$ & $\begin{array}{c}\text { Positive } \\
\text { n (\%) }\end{array}$ & $\begin{array}{c}\text { Tested } \\
\text { samples }\end{array}$ & $\begin{array}{c}\text { Positive } \\
\text { n (\%) }\end{array}$ & $\begin{array}{c}\text { Tested } \\
\text { samples }\end{array}$ & $\begin{array}{c}\text { Positive } \\
\text { n (\%) }\end{array}$ \\
\hline Children & - & - & 128 & 15 (11.7) & 128 & $18(14)$ \\
\hline HSCT & 91 & $4(4.4)$ & 102 & $12(11.8)$ & 102 & 14 (13.7) \\
\hline
\end{tabular}

DFA: direct immunofluorescence assay; HSCT: human stem cell transplant patients; PC: immunochromatographic point-of-care RSV Bio Easy ${ }^{\circledR}$; RT-PCR: reverse transcriptase-polymerase chain reaction. 
onset were detected exclusively with RT-PCR. For the HSCT group, both techniques detected positive cases five days after the onset of symptoms; however, the RTPCR had a higher sensitivity (Fig. 2).

The HRSV occurrence for the transplant patients was $15.5 \%(9 / 58)$ and was $20.9 \%(9 / 43)$ for the non-transplant patients (no statistical difference) (Table III).

The 19 HRSV-positive samples from the HSCT group were obtained from 15 patients; seven of these patients died (46.7\%). Five (33.3\%) of these deaths were temporally related to the RSV infection. Three (60\%) of the five deaths related to RSV infection occurred among transplant patients.

The monthly occurrence of HRSV was different for the two study groups. Among the children within the community, a viral detection rate of $14.1 \%$ was distributed during the autumn and winter months with a noticeable peak in April, which is consistent with the previously reported data on seasonality of the virus in Southeast Brazil (Pecchini et al. 2008). In the HSCT group, a viral detection rate of $18.6 \%$ was distributed from MarchJune with an absence of notable peaks which may be due

TABLE III

Human respiratory syncytial virus occurrence in transplant and non-transplant patients

\begin{tabular}{lccc}
\hline Population & $\begin{array}{c}\text { Positive } \\
\mathrm{n}(\%)\end{array}$ & $\begin{array}{c}\text { Negative } \\
\mathrm{n}(\%)\end{array}$ & $\begin{array}{c}\text { Total } \\
\mathrm{n}(\%)\end{array}$ \\
\hline Transplant & $9(15.5)$ & $49(84.5)$ & $58(100)$ \\
Non-transplant & $9(20.9)$ & $34(79.1)$ & $43(100)$ \\
\hline Total & $18^{a}(17.8)$ & $83(82.2)$ & $101(100)$ \\
\hline $\mathrm{p}$ & & 0.66 & \\
\hline
\end{tabular}

$a$ : for one patient, the information regarding transplant status was not available.

\begin{tabular}{|c|c|c|c|c|c|c|c|}
\hline \multicolumn{4}{|c|}{ HSCT group } & \multicolumn{4}{c|}{ Children group } \\
\hline DFA & RT-PCR & PC & $\begin{array}{c}\text { Samples } \\
\text { n(\%) }\end{array}$ & DFA & RT-PCR & PC & $\begin{array}{c}\text { Samples } \\
\mathrm{n}(\%)\end{array}$ \\
\hline+ & + & + & $3(3.3)$ & + & + & NA & $15(11.7)$ \\
\hline+ & + & - & $2(2.2)$ & - & + & NA & $3(2.3)$ \\
\hline- & + & + & $1(1.1)$ & - & - & NA & $110(85.9)$ \\
\hline+ & - & - & $5(5.5)$ & $/$ & $/$ & NA & 0 \\
\hline- & + & - & $6(6.6)$ & $/$ & $/$ & NA & 0 \\
\hline- & - & - & $74(81.3)$ & $/$ & $/$ & NA & 0 \\
\hline \multicolumn{3}{|c|}{ Total } & $91(100)$ & \multicolumn{3}{|c|}{ Total } & $128(100)$ \\
\hline
\end{tabular}

Fig. 1: comparison of human respiratory syncytial virus (HRSV) detection using three different techniques: direct immunofluorescence assay (DFA), immunochromatographic point-of-care RSV Bio Easy ${ }^{\mathbb{R}}$ assay (PC) and reverse transcriptase-polymerase chain reaction (RTPCR) in paediatric and human stem cell transplant patients (HSCT) patients. NA: not available; +: positive; -: negative; /: results were not found in the other possible combinations. to an outbreak that occurred in this period within the hospital ward and a result of the frequent re-evaluation of these patients to verify viral persistence. Importantly, the frequency of HRSV infections in both groups was the same in the first month of the study, which shows a possible link between the infection of HSCT patients and an increased circulation of the virus in the children of the community. Previous studies that analyzed the viral circulation and the rate of HRSV infection in immunosuppressed patients also demonstrated this relationship (Whimbey et al. 1996, 1997).

The detection of HRSV with RT-PCR was superior to all the other methods utilized, particularly in the samples of patients who had symptoms for longer than five days. The RT-PCR assay was able to detect three additional samples in the paediatric group and two additional samples in the HSCT group in comparison with the DFA, which was the test with the second highest positive rate for HRSV. These results were expected, particularly in
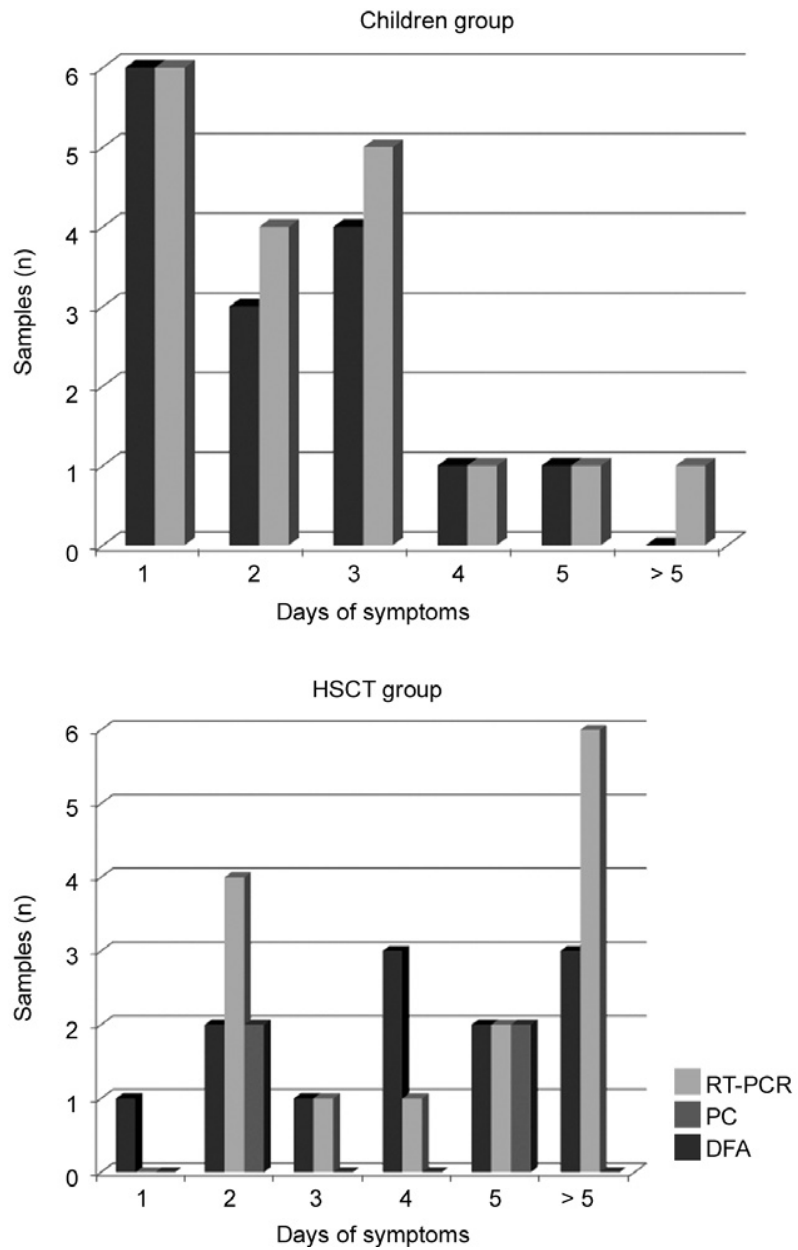

Fig. 2: distribution of the respiratory syncytial virus detection for the paediatric group and the human stem cell transplant patients (HSCT) group by assay according to the time of symptom onset until sample collection. DFA: direct immunofluorescence assay; PC: immunochromatographic point-of-care RSV Bio Easy ${ }^{\circledR}$ assay; RT-PCR: reverse transcriptase-polymerase chain reaction. 
cases of decreased viral shedding (Kuypers et al. 2009). It is also important to consider that viral shedding in immunosuppressed patients can be longer, and thus, viral detection can occur over prolonged periods.

Despite the convenience and speed of the results provided by the PC test, the low sensitivity of HRSV detection in the samples of the immunosuppressed patients does not justify its use in routine diagnosis. Furthermore, due to the commercial variabilities found between brands, it is important to compare different test brands and types (Kuroiwa et al. 2004, Deiman et al. 2007).

As shown by the high mortality rate temporally related to HRSV infections in the HSCT patients (33.3\%), HRSV represents a great risk for immunosuppressed patients; however, other respiratory viruses, such as flu, Adv and PIV, also have the potential to affect these patients (Rabella et al. 1999, Hassan et al. 2003). Thus, diagnosis by DFA is useful in these patients because it enables the detection of respiratory viruses other than HRSV. However, based on our concordance tests results, an association between the tests, such as DFA followed by RT-PCR for HRSV on negative samples, is the best way to diagnose high-risk patients. In conclusion, we suggest a continuous surveillance of respiratory viruses in high-risk patients using DFA as a routine method, but during high-risk seasons, a combination of molecular methods should be used to increase the efficiency of the diagnosis.

\section{ACKNOWLEDGEMENTS}

To Bioeasy, for providing the immunochromatographic test.

\section{REFERENCES}

Bellei N, Carraro E, Perosa A, Granato C 2007. Patterns of influenza infections among different risk groups in Brazil. Braz J Infect Dis 11: 399-402.

Deiman B, Schrover C, Moore C, Westmoreland D, van de Wiel P 2007. Rapid and highly sensitive qualitative real-time assay for detection of respiratory syncytial virus A and B using NASBA and molecular beacon technology. J Virol Methods 146: 29-35.

Ebbert JO, Limper AH 2005. Respiratory syncytial virus pneumonitis in immunocompromised adults: clinical features and outcome. Respiration 72: 263-269.
Erdman DD, Weinberg GA, Edwards KM 2003. GeneScan reverse transcription-PCR assay for detection of six common respiratory viruses in young children hospitalized with acute respiratory illness. J Clin Microbiol 41: 4298-4303.

Gardner PS, Turk DC, Aherne WA, Bird T, Holdaway MD, Court SD 1967. Deaths associated with respiratory tract infection in childhood. Br Med J 4: 316-320.

Hassan IA, Chopra R, Swindell R, Mutton KJ 2003. Respiratory viral infections after bone marrow/peripheral stem-cell transplantation: the Christie hospital experience. Bone Marrow Transplant 32: 73-77.

Kesson AM 2007. Respiratory virus infections. Paediatr Respir Rev 8: $240-248$.

Kuroiwa Y, Nagai K, Okita L 2004. Comparison of an immunochromatography test with multiplex reverse transcription-PCR for rapid diagnosis of respiratory syncytial virus infections. $J$ Clin Microbiol 42: 4812-4814.

Kuypers J, Campbell AP, Cent A, Corey L, Boeckh M 2009. Comparison of conventional and molecular detection of respiratory viruses in hematopoietic cell transplant recipients. Transpl Infect Dis 11: 298-303.

Landry ML, Ferguson D 2000. SimulFluor respiratory screen for rapid detection of multiple respiratory viruses in clinical specimens by immunofluorescence staining. J Clin Microbiol 38: 708-711.

Pecchini R, Berezin EN, Felício MC 2008. Incidence and clinical characteristics of the infection by the respiratory syncytial virus in children admitted in Santa Casa de São Paulo Hospital. Braz J Infect Dis 12: 476-479.

Rabella N, Rodriguez P, Labeaga R 1999. Conventional respiratory viruses recovered from immunocompromised patients: clinical considerations. Clin Infect Dis 28: 1043-1048.

Reed LJ, Muench 1938. A simple method of estimating fifty percent endpoints. Am J Epidemiol 27: 493-497.

Whimbey E, Champlin RE, Couch RB 1996. Community respiratory virus infections among hospitalized adult bone marrow transplant recipients. Clin Infect Dis 22: 778-782.

Whimbey E, Englund JA, Couch RB 1997. Community respiratory virus infections in immunocompromised patients with cancer. Am J Med 102: 10-18. 